\title{
Chapter 5 \\ Coping with Rural Transformation and the Movement of Workers from Rural Areas to Cities: The People's Republic of China Sunshine Project
}

\author{
Li Wang and Greg Shaw
}

\section{Background}

Since the reform and opening up that began in 1978, extensive and profound changes have taken place in every aspect of Chinese society. The market economy has rapidly developed, and the scale of economic activity continues to grow such that the People's Republic of China (PRC) now is recognised as the world's second largest economy. The PRC continues to develop its industry activity, particularly secondary industries which have taken on increased prominence in the PRC economy, as the PRC strengthens its position as the world's manufacturer. Industrialisation has brought with it a significant urbanisation of Chinese society such that by 2012 for the first time, a majority of Chinese people lived in urban environments. The PRC entry in the World Trade Organization (WTO) in 2001 is one of the hallmark features of its national development strategy. Policy initiatives that have driven these achievements have resulted in a transformation of the PRC economy, though they have also impacted on the PRC political, environmental and social system. Additionally, there has been significant increase in agricultural production, despite declining arable land. More efficient farming techniques requiring less labour and the consolidation of smallholder plots into larger farms, in concert with increasing populations, have created an excess of labour in rural areas. However, as vocational opportunities in rural areas have changed or decreased, demand for labour in urban and industrialised areas has increased, as the PRC expanded its industrialised activity and output. This has driven labour demand and

\footnotetext{
L. Wang $(\bowtie)$

UNESCO International Research and Training Centre for Rural Education (INRULED),

Beijing, People's Republic of China

G. Shaw

School of Education, Charles Darwin University, Darwin, Australia

e-mail: greg.shaw@cdu.edu.au
} 
provided opportunity to tap into excess labour resources in rural areas. To facilitate the mass movement of labour from rural areas into industrialised and urban areas has required removal of systematic and structural impediments that have hindered the socio-economic development. Such impediments particularly affected rural workers. However, by creating diverse opportunities for employment for rural migrant workers in towns and cities and factories and through facilitating retraining and support for these workers, the PRC has achieved what in many ways is a miracle of social and vocational readjustment.

\section{Rural Labour Migration: Challenges}

Based on current vocational opportunities, there are 280 million surplus labourers in rural PRC, who in the past would have worked in vocational activity in rural areas or would have been peasant farmers. It is estimated that an additional six million unemployed rural workers become available each year. Such a significant number of people with vocational aspirations, and who need income in order to survive and to provide for their families, generate a significant potential social disruption for the Chinese society if not addressed. Of these surplus labourers, $87.8 \%$ have an educational level of junior high and below, only $0.52 \%$ of rural labourers have a college or higher education, and only $9.1 \%$ have received professional training. While such educational background may have been satisfactory for work and vocational activity in rural industries, it does not adequately reflect the particular skill and education needs that labourers and workers require in order to participate as skilled workers in industrial and other occupations in urban areas.

Therefore, it is critically important for the PRC's ongoing development, and for the provision of the needs of individuals, that education and training of rural workers suitable for employment in urban and industrialised settings be provided. Strengthening the education and training of rural people to help improve the quality of their lives and enhance their employability are vital. Increased education, and focused and specific training, improves the income generation potential of the PRC's surplus rural labour and facilitates a smooth and socially stable transfer of work from agrarian activity in rural contexts to non-agrarian activity in urban contexts. However, this has presented challenging policy implications for the PRC.

Retraining of surplus rural labour in order to meet labour demand in the PRC's rapidly industrialising sectors is only part of the story. The surplus rural labour is located in rural areas, whereas the majority of development and industrialisation is taking place in the major urban areas, although there is significant urbanisation and industrialisation of many regions and areas in the PRC that were in the past considered rural.

Consequently, two major population adjustments have been occurring in the PRC. First, workers are displaced as work opportunities dry up in rural areas or where smallholding blocks farmed by individual farmers are consolidated into larger farms requiring fewer workers. Such displaced workers will either naturally migrate to urban and industrialised areas in search of work or quite often as a result 
of land acquisition by will be given favourable treatment in taking up housing in urbanised centres. Such physical relocation of accommodation involves relocation not only of the labourer but also of their family. Such migrations are usually permanent, as they involve a relocation of their and their family's accommodation. In any case, unless the persons and their family have alternate sources of income (such as a pension), they will be in need of money in which to live.

A second population migration occurs on an annual basis. This is often referred to in the PRC as 'the floating population', and the numbers are staggering. In 2005, the numbers were estimated as 150 million people. Migrant labourers mostly come from the PRC's underdeveloped western and central provinces such as Sichuan, Anhui, He'nan and Gansu and mainly head to urban areas, south-eastern coastal locations and metropolises like Beijing and Shanghai, as well as nearby townships, surrounding counties, small cities and provincial capitals. By 2020, it is estimated that another 100-150 million 'surplus' rural labourers will join the rural labour migration, with estimates that the total numbers will be in excess of 300 million people. These workers, move to towns and cities either in search of work or to take up work. Then, every Spring Festival and during the two other major holidays, when most industries closed down, these migrant labourers catch millions of buses and trains and migrate back home in order to have time with their families during the most significant social reunion time within Chinese culture.

Rural-urban migration has had an economic impact on the PRC. In 2003, it was estimated that labour migration from rural to urban areas contributed about $16 \%$ of the total growth of the PRC's GDP over the previous 20 years (Huang and Pieke 2003).

In 2001, the rate of urbanisation of the PRC was 37\%. Following the reform and opening policy (Sun 2011), urbanisation in the PRC increased in rate. By the end of 2011, the mainland of the PRC had a total urban population of 691 million or 51.3\% of the total population, rising from $26 \%$ in 1990 , and it is estimated to be $70 \%$ by 2050 (Knight et al. 2011). Additionally, migrant labourers are young and $70 \%$ are between 16 and 35 years of age, and most have completed a junior middle school level of education (9 years in school). Most migrant labourers earn a monthly income from 300 Yuan (US\$36) to 600 Yuan (US\$72). About one-third of migrant labourers are female. Most migrant labourers are employed in blue-collar jobs which urban dwellers are unwilling to undertake.

In recent years, government policy has gradually reflected by greater appreciation of the contribution that rural migrant labourers make to the economy and the need to address inequities in the labour market and in social justice. However, even though many policies have been developed to protect rural migrant labourers and to promote rural labour migration, issues such as poverty and poverty reduction, especially in terms of incapacity and social exclusion of rural migrants, were not addressed seriously prior to 2004. Fundamentally, the PRC government needed to address the growing problems presented through massive unemployment and underemployment of rural people and the inherent issues of poverty and restriction of national growth and prosperity for all. 


\section{The Sunshine Project}

One concrete example of this policy shift is the Sunshine Project (Shaohua 2005), launched in 2004 jointly by six national ministries, namely, the Ministry of Agriculture (MOA), Ministry of Labour and Social Security (MOLSS), Ministry of Education (MOE), Ministry of Science and Technology (MOST), Ministry of Construction (MOC) and Ministry of Finance (MOF). The Sunshine Project is one of the major components of the Training Plan for Nationwide Rural Migrant Workers (2003-2010).

The programme is scaffolded by action research (De Vos et al. 2011) and involves social science researchers and educators in designing, monitoring and evaluating the specific components and activities of the programme. These include skills training (Majumdar 2011), practical focused education (such as law and health awareness), network building (Kilpatrick et al. 2011) and social capital building (Bird Hulme et al. 2002), which were executed in eight selected pilot sites at the beginning of the project. Generally, the programme examines, advocates and implements proactive, positive and practical policy changes to reduce poverty among rural labour migrants in terms of addressing capacity and social exclusion, especially from a gender perspective. The programme promotes local development through rural labour migration and attempts to establish 'win-win' partnerships between different regions (sending and receiving areas; western, central and eastern regions; underdeveloped and developed regions). The programme is primarily about supporting rural people in undertaking the substantial vocational and social changes occurring in their lives.

The Sunshine Project is the implementation of a key and proactive policy shift undertaken by the PRC government. It is not one project, but as indicated above, is a series of activities, policies and national and local initiatives all centred on various aspects of training and support of surplus rural labour in order to provide for the labour needs of urban and industrial the PRC. Additionally, it is a social reconstruction instrument, reprioritising and reorganising the structures of Chinese communities and vocational and industrial activity. It is partly a response to changes that occurred naturally as the PRC, like all other countries, continued to urbanise and industrialise. However, it is also a strategic long-term social planning exercise, to ensure that Chinese society and its economy transition into modern and stable entities, with minimal social and political disruption. Indeed, it is the world's largest project focused on retraining for rural workers.

\section{Conditions for the Sunshine Project}

It is internationally widely held that the PRC is indeed an economic miracle (Chen et al. 2009). Coming from a very low base of development and extreme levels of poverty, the PRC government over the last 50 years has steered a remarkable 
course of development not only for the nation but also for hundreds of millions of its citizens. The PRC now stands proud as the second largest economy in the world, and in times of great uncertainty, and with subdued economic development across most of the world, the PRC stands almost alone with continued economic development, activity and growth. However, such success has not come without its problems (Zhang 2012) and without the need for major structural reform (Prasad 2009).

The PRC's economic growth has come primarily from its industrialised base. Many comment on the PRC being the factory to the world (Chow 2011). The most significant resource that has allowed the PRC to achieve this status is the sheer numbers of workers viable to participate in industrial vocations and the relatively low base of salaries that they are paid. In addition, the participation of state-owned and state-backed enterprise has allowed substantial investment in industrial capacity and significant economies of scale across a whole range of associated factors such as logistics and infrastructure. In some ways, the PRC is an enterprise. National development of infrastructure such as railway, road transport power generation and water resources has become not only a way of improving the lives of people who benefit from this, but ensures efficient and effective environments in which to locate industry and to facilitate supply of raw materials and export of finished products. Such national projects as well rely upon a significant number of excess rural labourers, as does the burgeoning building and housing construction industry.

This economic growth has brought about an enormous and rapid change in population distribution. During the last two decades of the twentieth century, the PRC's rural population remained above 800 million people - two to three times that of the urban population. However, by 2010, the rural population was equal to urban population, and, from about that year, a reverse trend was obvious, whereby urban populations were larger than rural populations. Such population swing from rural to urban has exacerbated the natural significant population growth of the PRC and is reflected in the growth of towns and cities. There are over 120 cities and built-up areas in the PRC with a population over one million people (PRC National Bureau of Statistics 2012). Also, significant areas on the east coast of the PRC, while may be classified as rural, have very high population densities and 'villages', towns and cities that are distinctly urban'.

This substantial shift in population location, from rural to urban, has occurred relatively quickly and as noted is a consequence of changes in agricultural activity and increased opportunities for employment with relatively high salaries in emerging manufacturing sectors located in urban areas. However, this population adjustment has resulted in substantial disruption and unemployment or under employment (Ma 2012). The task is to match the unemployed rural labour with jobs. This is something that the Sunshine Project attempts to do. Balancing the itinerant rural labour supply against the labour market is a delicate issue, and it is critical that the PRC achieves this as millions of discontented and unemployed rural workers will not help social cohesion and stability.

Being the 'factory to the world' relies upon other countries, particularly developed countries, to have sustained economic activity and prosperity placing demand 
on the goods that the PRC produces. However, the continuing economic crisis that began in 2007, and the increased instability apparent from the economic and political crisis in Europe, has placed additional downward pressure on imports of PRC goods. Consequently, the PRC has suffered a downturn in the growth rate (Liang 2012). And if the PRC suffers further slowing and problems with its overpriced housing markets, the world will be in for further pain and suffering. Yet the PRC does have a significant local market, and 1.2 billion consumers can make a major difference in ensuring that manufacturing and economic activity continues to grow.

In the past, PRC policy placed major restrictions on the movement of people through the household registration system, in order to ensure a balance and status quo. However, since 2000, the government has implemented a number of policies both allowing greater flow of labour and also to protect migrant workers' rights and interests. Consequently, the number of rural workers who migrated and found jobs in urban areas has changed from approximately 98,000,000 in 2003 to more than 145 million in 2009 (Giles et al. 2012).

\section{The Sunshine Project Methodology}

As a series of policy initiatives focused on bringing about greater efficiencies in the labour market and matching unemployed labour to potential jobs, the Sunshine Project has significant focus on training and matching people to jobs. It is necessary for the government to undertake policy intervention to facilitate the social, population and vocational adjustments consequential to industrialisation, urbanisation and changing agricultural practices and organisation. In addition to helping in a redistribution of labour, there was in the PRC significant demand on increasing the knowledge and skill base of workers, to take best advantage of industrial expansion and construction. In order to bring about the development of knowledge and skill bases of workers, the Sunshine Project is firmly located in Technical Vocational Education and Training (TVET) approaches.

The Sunshine Project is grounded in philosophical and policy positions, and to put the policy into practice, the six government ministries responsible for the project developed a National Migrant Worker Training Plan (Shaohua 2005). This plan used two phases built around the major focus and approaches of the project. Each phase reflected a different focus in terms of numbers to be trained, although the main activities were preemployment training for farmers planning or wishing to go to nonagricultural industries, explicit vocational training linked to work ready skills that were in demand and on-the-job training. The training activities were closely linked with skills and jobs that the labour markets were indicating were needed, and so there were attempts at having a strong match and link between the supply and demand of skills. This approach is also an employment-orientated approach, in that it is focused on providing people with the skill sets necessary to be able to get a job. This also recognised the importance 
of skill upgrade and addressing new workplace skills, as well as the necessity to facilitate worker migration.

Implementing this project across thousands of communities and coordinating the activities of six ministries were no easy task. It required high level of collaboration at various levels of government and across communities. While many activities were operating concurrently across multiple communities, the approach was strategic and focused and required distinct steps in action. In particular, it was necessary to access current and accurate figures on unemployment in various communities and under employment in various industries and to strategically match these taking into account the skill of education base of the workers and the skills required of the work.

The government's role in planning and implementing the programme was to act as a facilitator and an enabler. In this, the PRC government committed significant funds in order to operate new and expanded programmes and also to provide training incentives. The government did not actually do any of the training or other on the ground activities, but rather, identified need, identified potential partners and providers and provided the money needed at each step and for each process. Existing and upgraded training institutions, public and private, undertook the training. These training institutions needed to pass quality checks to ensure they had capacity, resources and appropriately trained and qualified staff to undertake the training activities.

\section{The Sunshine Project Implementation}

Under the work plan, the project there was a focus on key issues each year from 2004 to 2010. In 2004, the focus was on rural labour transferred to nonagricultural industries, providing skilled labour for major grain-producing areas in the PRC, generating employment in poverty-stricken areas and short-term prevocational training programmes. In 2005, project activity increased, and a distinct need focus based on regions (eastern, central and western regions) was taken in the provision of training subsidies. In 2006, funding for subsidies was increased, and new programmes were rolled out to assist farmers in finding new jobs and assist in their transfer to these. There was also a focus on improving quality of project activities. In 2007, it was decided to extend training periods to allow more time to cover skills at the depth required. Also, new programmes were introduced focused on skill upgrade and entrepreneurial and business skills. In 2008, additional programmes were rolled out, with a continued focus on longer, in-depth and quality training. In 2009, activities across all sub-programmes of the project continued; however, there was an increased focus on agricultural-related industries following significant improvements in agricultural practice and in the use of technology in agriculture. This focus continued into 2010 picking up on other rural service industries and rural support industries. Therefore, the Sunshine Project is not just about assisting in the transfer of populations from rural to urban but also 
significantly about helping rural farmers come to grips with and be qualified for work in a modernised agricultural economy.

One feature of the project has been the provision of various employment support and service activity. For example, in 2006 in Hubei Province, an initiative was set up to offer information to rural workers and to bring workers in contact with industry representatives through facilitating labour fairs. Over 100 labour fairs were held in 2006 offering more than 300,000 jobs. The fairs brought together labourers and employers allowing for skill matching to take place. However, it was recognised that the process is not just a matter of matching people to jobs, but is also about empowering workers through better understanding of workers' rights. To help inform workers of their rights and to offer support in cases of abuse, numerous legal aid centres for migrant workers were established.

In the implementation of the project, a decision was made to separate the administration of activities from the actual training and activities themselves. Training providers, legal aid centres, employment agencies and other groups involved in on the ground implementation by and large did not have to worry about the funding processes, but could concentrate on what they were contract to do.

Quality control was ensured through a number of mechanisms. As mentioned, training providers and training centres needed to obtain accreditation before they could access funds and provide training. These quality requirements were monitored throughout the project. Likewise, training providers had to guarantee the length, content, skills and quality of their training programmes. In particular, they had to demonstrate that their training programmes linked to the goals that had been set. Training programmes very often were linked to formal qualifications, which have contributed to the further development of the PRC's qualifications framework. Additionally, such formal recognition provided incentives to farmers to undertake training and provides a mechanism for employers to recognise skill sets as defined by the qualification.

The Sunshine Project has involved literally hundreds of subprojects since its inception covering a broad range of training and other activities. What follows is a description and analysis of two projects.

\section{Retraining of Rural Workers for Changed Rural Industry}

As indicated above, the rapid transition of the PRC towards a market economy in recent years and the modernisation of agricultural industries, resulting in more efficient agriculture requiring less per capita labour per output, have created an enormous surplus of rural workers. As a result, the Sunshine Project has paid particular attention to creating mechanisms for the relocation of rural workers to nonagricultural industries in urban areas. However, the PRC government recognises it is equally important to develop skills and knowledge of some rural workers for work in agricultural industries and agricultural support industries in order to harness the full potential of a modernised and multifaceted agricultural sector (Nuo and Ligang 2012). 
In order to achieve a highly productive and efficient rural sector, strategies need to be focused and applied at the local or industry level. Following this approach, the municipal government of Wuhan with the help of the Sunshine Program's platform for entrepreneurial training undertook steps in the form of preferential policies and training practices focused on agricultural industry. One example of this addressed policies and practices in the pork industry of the province through farmer entrepreneurial training in the Wuhan Sunshine Program (Li 2012a).

The pig industry has been one of the remarkable miracles of modern agriculture. Traditional pig farming involved smallholders raising a few sows in open fields, with limited shelter and depending upon available food often with low protein content. The consequences were low efficiencies in the conversion of food into meat and high labour demands. Contrasting with this is modern pig farming where decades of genetic breeding have resulted in pigs that mature rapidly and that are extremely efficient in food conversion ratios and with sows that have large uniform litters. Coupled with this are intensive pig-farming practices with environmentally controlled restricted exercise habitats, formulated high-protein food that is constantly available, the use of antibiotics and other approaches to reduce mortality and increase metabolic efficiency. Pigs, along with poultry, have become high-tech agricultural activity, which can be managed using technology to minimise labour input. In the PRC the pig husbandry approaches have changed in many locations from the traditional methods and practices based on single farmer households to industrialise large-scale operations. In order to be able to engage in such large-scale high-tech operations entrepreneurs need capital for development of local capacity and high-level managerial and technical expertise. In addition, labour to operate such high-tech contemporary piggeries requires matching skills and training that goes beyond that required in traditional pig-farming practices, where typically skills were passed down from father to son and mother to daughter. Increasingly as well, pig-farming enterprise needs to not only use the latest technology, but to do so within a low-carbon ecological deeply rooted in the local context.

The Wuhan's Sunshine farm enterprise training programme was extended in the form of an entrepreneurial training programme at the Agricultural School of Wuhan focused on pig husbandry. The programme was run over 15 days by teachers and experts from the university and was provided free of charge. This concentrated training course involved entrepreneurial design, market research, application of modern pig-raising methods through practical learning tasks and business development. In addition to the agricultural training that farmers and labourers received, there was assistance provided to farmers through various agencies in accessing credit for capital development and also to establish networks for ongoing field extension support by agricultural offices.

One of the outcomes of this programme was the regeneration of old farms, which were renovated, and facilities improved. In some cases, value adding occurred through construction of piggeries with recycling of waste into biogas powergeneration facilities at the piggery creating an integrated system for the use of biogas slurry and residues and providing some power back to the piggery operation. 
The pig-raising programme was initially provided to 97 people from the districts of Huangpi, Jiangxia and Caidian, including farmer households specialising in raising pigs and farmers willing to raise pigs. The implementation of the programme involved ten experts and professors from the university who successfully delivered lectures concerning practices for farmers to start their own business and the application of new technologies for standardised ecological pig-raising enterprise. The training contained a mix of theory and practice and also included field trips to pig farms and practical experience in a range of operations. The programme cultivated among the participants entrepreneurial consciousness, inspired them to start their own businesses and taught them methods to start new business ventures. In addition, close liaison between the farmers, local agricultural extension officers and university teachers ensured a common focus and built a supportive network, which has helped to sustain ongoing enterprise activity.

One of the impacts of this project has resulted in noteworthy increases in farmers' income, and this is in line with impacts of other Sunshine subprojects and is one of the key goals of the policy driving the Sunshine Project. Also, the entrepreneurial training encouraged farmers to create their own business ventures. This specific training has the long-term potential of generating additional positive benefits such as job creation and increased employment. These effects can contribute to a generalised improvement of prosperity in rural areas and to the generation of a virtuous cycle to pull rural workers out of poverty.

\section{Training Rural Labour for Urban Industrial Activity}

The PRC's economic development has been fuelled by the growth of its market economy and has led to rapid industrialisation and increased urbanisation. While the rural population of the PRC is still very large, it has shifted from being the majority of people to where more people now live in urban communities than in rural communities. The significant shift in population coupled with major shifts in industrialisation and work practices has resulted in misalignments of labour markets. The rapid urbanisation processes associated with these population changes present potential problems of social disharmony and economic disparity if adjustments that allow for a smooth absorption of the excess rural labour force into the urban market structures are not made.

However, it is not desirable to simply transfer excess rural labourers, with skills in rural industries and lifestyle, into urban settings and vocations where different skills are required. The successful transfer of excess rural labour to take up new roles requires different sets of skills, and the transferring rural labourers need information to best access and harness job opportunities. Only when rural labourers are provided with the skills and information that they need can they fully and effectively participate and prosper within the developing urban economic and social structures. 
Given these challenges, systematic 'bridges' are required to facilitate rural workers in obtaining jobs in urban areas and to facilitate their and their family's migration. A sub-programme of the Sunshine Program in Yunxi County (northwestern Hubei Province) represents a success story in assisting excess rural workers effectively take up employment opportunities in urban settings. The programme aimed at establishing a smooth connection between rural workers, who were previously farmers, and companies operating various manufacturing enterprise in urban settings who are in need of workers. The sub-programme focused on identifying employment opportunities and then identifying the skill set needed in order to meet the required job skills. In identifying the skill sets required for employment the sub-programme focused on strengthening linkages between five major vocational training schools and factories in order to best facilitate the development of appropriate and focused vocational skills that the migrant workers needed in order to be skilled factory workers.

In this process, the Sunshine Program provided tangible support to assist vocational schools to meet industry training needs by matching vocational schools and their specialty training programmes with the companies' needs. The process was focused on ensuring that these potential employees could be successfully matched with companies with employment needs and that these migrant workers could find a job as soon as they finished their training. In addition to funding provided by the Sunshine Project, Yunxi County spent over two million Yuan (US\$320,000) towards the training of these prospective migrant workers. The county took on an important role in caring for and facilitating training and employment opportunities for its own citizens. A county-based training system linking these five major training centres for increased efficiency was also established in order to provide the appropriate training and best guarantee employment in urban areas of surplus rural labour in the county.

The Sunshine Project subproject in Yunxi County has had significant impact and success. It provides a useful model in connecting schools and industrial employers to ensure most effective matching of vocational skill needs and the training required to achieve these. Additionally, it demonstrates the effectiveness of bringing representatives of industry, located in urban settings, into a rural community in order to liaise directly with training facilities and to establish mechanisms for recruitment. As a result of this activity, the five main county vocational and technical schools set up partnerships and agreements with the Shenzhen Foxconn Electronics Group, the Hubei Zhuoyue Construction Group and the Dongfeng Motor Corporation for migrant worker employment and the skills required for this. These partnership agreements not only facilitated linkages for employment but also indicated the training required. These industries were able to negotiate with the training schools to ensure that the particular skills they required for the industries were addressed.

Additionally, skilled technicians from these companies assisted the vocational schools to develop appropriate curriculum and training resources. The training therefore became quite focused on ensuring that these rural workers were job ready for these industries and, therefore, readily employable. For example, between 
2005 and 2006, approximately 7,430 technicians undertook training through these county vocational schools in collaboration with companies mentioned above and were successfully employed in positions that paid significantly more than they are able to achieve in the past (PRC Government 2012).

Ten specialised courses were developed, and these included cooking, electronic assembly, electrical engineering and construction. These training programmes not only reflected the needs of companies that had established partnership agreements but also linked to national qualifications frameworks and national and international standards. The standard of training delivered was of a high quality, and these excess rural labourers were highly motivated to be successful because successful completion of training nearly always guaranteed employment. Consequently, some of the areas of skills development achieved in this programme have received national recognition, and this sub-programme that was set up to meet a local need has resulted in graduates being transformed from displaced rural labourers into wellknown and respected expert workers. For instance, 'Yunxi construction workers' that emerged from this programme have a reputation across the PRC as being the leaders in the field.

Graduates of this sub-programme experienced a substantial increase in income levels upon employment and a widening of employment perspectives and opportunities. This success has been mainly due to the adoption of a multiparty approach that tailored both training and placement opportunities to the participants' characteristics and expectations.

\section{Rural Transformation and the Sunshine Project}

The concept of rural transformation can have multiple meanings. It has been used to describe a vision and process of change for the development of rural communities through education focused on national and global developmental goals (INRULED 2001). Such vision often emphasises poverty alleviation and national and community development goals. This view was strengthened somewhat in a recent publication where the authors elaborate that rural transformation ' $\ldots$. is all about seeking to bring about improvement in the living conditions of the farmer, the artisan, the tenant and the landless in the countryside' [our emphasis] (Ahmed et al. 2012). The concept of rural development is closely linked to the ways in which the term rural transformation is used in a range of literature. However, some have argued that any aspect of rural transformation needs to go beyond the physical transformation of rural environments and incorporate transformations of people. Shaw (2011) makes this point and links processes of education and training, which are focused on the person, directly to transformational outcomes which impact the person as well as the community.

The Sunshine Project has as a primary goal the redistribution of labour from an agrarian economy into an industrialised economy and to facilitate the skills development required for migrant workers to be able to take up jobs in the PRC's new 
economy. The Sunshine Project is also about facilitating a smooth migration processes with minimal social disruption. Such migration in the long term is tending towards increased congregation of people in urban communities. That is, rural people are migrating to urban centres in order to work and in the long term to live. However, as indicated previously in this chapter, a significant number of rural migrant workers also constitute a floating population of several hundred millions of people, commuting annually to and from workplaces in distant urban centres. The outcome of the Sunshine Project as a mechanism to facilitate social adjustment to changing social and economic circumstances and to industry requirements has significant other 'transformational' outcomes. As noted, these migrant rural workers have the capacity to earn incomes that are substantially more than what they would receive if they had remained in (or had the opportunity to remain in) their traditional employment vocations. Thus, increased incomes, much of which is sent back 'home' has a direct impact on improving the lives and lifestyles of people living in rural communities. The PRC is experiencing a significant home-grown consumer-led economic boom. Salaries have been rising steadily over the last decade, and standards of living have increased significantly. The PRC is the world's largest consumer society, and substantial improvements to lifestyle through improved housing, communications, entertainment, recreation, health services and other 'consumables' have been achieved in recent years.

Additionally, and very significantly, the Sunshine Project has a direct impact on improving the education of Chinese people. Much of these educational activities are focused on skills development (Ahmed et al. 2012), but the development of skills also requires and involves other educational outcomes. Migrant workers for vocational occupations in industrial settings often need high-level contemporary skills such as skills required in the modern construction industries, electronics industries, manufacturing, management and skills for service industries such as tourism and hospitality. When people undertake education and training, they often have a transformational experience (Mezirow 1991; Newman 1994; Reading et al. 2006; Shaw 2011, 2012). In the case of migrant workers undertaking training under the Sunshine Project, these transformational experiences can be various, but include having a new perspective on work and a deeper understanding of theoretical underpinnings of practice. That is, they better understand how things work. Other transformations may be more related to paradigm shifts where people start to view the world and their values in completely different ways. However, when training is coupled with new work experiences in new contexts (i.e. urban or increasingly urbanised rural contexts), this can lead to additional transformative experiences. Finally, education, particularly vocationally orientated, can have an empowering outcome as was demonstrated and used by Freire (1972). People are transformed when they gain skills and knowledge and are able to apply these in their daily lives. When people have skills and knowledge, they are in a better position to actually do something about changing their own lives, to make vocational choices, including entrepreneurial activity.

Such a view of transformation is important. The significant vicissitudes taking place in the PRC, from an agrarian economy to an economy dominated by 
manufacturing and construction, and from a rural society to an urban society, are changing the very fabric of Chinese society. Some of these changes have come about through other policy decisions as well or through processes of opening up and modernisation. No matter what the driving forces, the PRC is undertaking change. Indeed, the whole society is transforming. However, in this process, through education, work and through political reforms, individual people are changing and being transformed at the personal, family and community levels. As people transform in response to societal changes, they also are in a better position to transform their society. As rural people become more empowered through knowledge and skills, and through income earning opportunities, they will be and are in a stronger position to take an active role in the directions that the transformations of their lives and communities take.

\section{Conclusion}

The Sunshine Project is described as the world's largest project for rural labour transfer training ( $\mathrm{Li} 2012 \mathrm{~b}$ ). It was set up through various policy initiatives to facilitate a process of structural adjustment of labour markets and habitation in the PRC. This structural adjustment is required in order to ensure unemployed or underemployed rural labourers have an opportunity to secure paid livelihood in the rapidly developing industrial, construction and service industries of the PRC. The project is focused on facilitating matches within the job market and providing pathways for training and migration for millions of rural PRC workers. The Project is essential for PRC ongoing development strategies as it enables efficiencies essential for successful further development of the PRC's economy. However, as the PRC continues to develop and undertakes massive adjustments to industries, there are substantial pressures on people, communities and the environment. These changes are sometimes referred to as 'transformational', in the sense that people, communities and environments are being radically changed. Some of these changes are unavoidable and indeed desirable, whereas others generate tensions within the fabric of society and also have significant environmental impacts. This chapter has only addressed some of these changes and issues focused on rural labour training for undertaking employment within various industries in urban contexts, the retraining of rural labourers to take advantage of the latest agricultural technologies for re-employment in rural contexts, and has to some extent addressed some of the issues to do with population adjustments and internal migrations in the PRC.

In highlighting some of the outcomes of the Sunshine Project, we have indicated that the education and training activities conducted under the Project not only have important impacts on matching workers with skills with employment but that also education and training can have a positive transformational outcome for the individuals undertaking these. We further highlight that individuals transformed by education and training and employment opportunities can have a transformational impact on their families, communities and ultimately on the nation. 
The Sunshine Project continues to receive support from the highest level of the PRC government and has become a key policy activity area impacting broadly across the PRC and most industries and has made a substantial contribution to the continuing ongoing development and stability in the PRC, and that benefits the whole world. Fundamental to the Sunshine Project is a focus on the person, on their livelihoods and well-being and on raising income levels and alleviating poverty and helping people live fulfilled lives. In this respect, the project is clearly successful.

Open Access This chapter is distributed under the terms of the Creative Commons Attribution Non-commercial License which permits any non-commercial use, distribution, and reproduction in any medium, provided the original author(s) and source are credited.

\section{References}

Ahmed, M., Wang, L., et al. (2012). Education and training for rule transformation: Skills, jobs, food and green future to combat poverty. Beijing: UNESCO-INRULED.

Bird, K., Hulme, D., et al. (2002). Chronic Poverty and Remote Rural Areas. Chronic Poverty Research Centre Working Paper No. 13. Available at SSRN: http://ssrn.com/abstract=1754490 or http://dx.doi.org/10.2139/ssrn. 1754490

Chen, Z., Ren, Z., et al. (2009). Research on essence and feature of [the People's Republic of] China's economic development miracle based on the analysis of route evolution since reform and opening-up. Journal of Finance and Economics, 2009(5).

Chow, P. C. Y. (2011). [The People's Republic of] China as the world market and/or the world factory in the global economy. In Y.-C. Chuang \& S. Thomas (Eds.), [The People's Republic of] China and the world economy: [The People's Republic of] China's economic rise after three decades of reform (pp. 37-39). Berlin: LIT Verlag Münster.

De Vos., Delport, A. S. C., et al., (2011). Research at grass roots: A primer for the social science and human professions. Van Schaik Publishers: Pretoria, South Africa.

Freire, P. (1972). Pedagogy of the oppressed. Harmondsworth: Penguin.

Giles, J., Park, A., et al. (2012). Weathering a storm: Survey-based perspectives on employment in [the People's Republic of] China in the aftermath of the global financial crisis. The World Bank: Development Research Group.

Government of the People's Republic of China. (2012). Seamless connection: Yunxi rural labor training. Retrieved July 10, 2012, from http://www.nmpx.gov.cn/jiangyanjiaoliu/ t20060707_45332.htm

Huang, P., \& Pieke, N. F. (2003). [The People's Republic of] China migration country study. Migration development pro-poor policy choices in Asia. London: Department for International Development.

INRULED. (2001). Education for rural transformation: Towards a policy framework. Beijing: UNESCO-INRULED.

Kilpatrick, S., Abbott-Chapman, J., et al. (2011). Identifying the characteristics of rural learning communities: Implications for rural development. Darling Heights: SPERA.

Knight, J., Quheng, D., et al., (2011). The puzzle of migrant labour shortage and rural labour surplus in [the People's Republic of] China. [The People's Republic of] China Economic Review, 22(4), 585-600.

Li, X. (2012a). Rural migration in [the People's Republic of] China: Operational mechanism and effects of [the People's Republic of] China's sunshine project. Beijing: School of Economics and Resource Management, Beijing Normal University. 
Li, X. X. (2012b). [The People's Republic of] China's sunshine program: The world largest project for rural labor transfer training. Beijing: Research Center for Scientific Development Concept and Sustainable Economic Development, Beijing Normal University/UNESCO International Research and Training Centre for Rural Education (INRULED), [The People's Republic of] China Translation/Publishing Corporation.

Liang, Y. (2012). [The People's Republic of] China's short-term and long-term development after the 2007 global financial crisis: Some critical reflections. Chinese Economy, 45(1), 3-7.

Ma, L. (2012). Critical evaluation of the new rural-urban labor mobility in [The People's Republic of] China: Reasons and effect of rural-urban labor migration on urban and rural labor market. Asian Social Science, 8(3), 321.

Majumdar, S. (2011). Emerging trends in TVET in Asia and the Pacific Region: CPSC's response. In S. Majumdar (Ed.), Emerging Challenges and Trends in TVET in the Asia-Pacific Region (pp. 3-17). Sense Publishers: Rotterdam, The Netherlands.

Mezirow, J. (1991). Transformative dimensions of adult learning. San Francisco: Jossey Bass.

National Bureau of Statistics of [The People's Republic of] China. (2012). Annual Data, Population, 2011, retrieved from http://www.stats.gov.cn/english/statisticaldata/yearlydata/, November 13, 2012.

Newman, M. (1994). Response to understanding transformation theory. Adult Education Quarterly, 44(4), 236-242.

Nuo, W., \& Ligang, X. (2012). The subjects and forms of training. In X. Li (Ed.), [The People's Republic of] China's sunshine program: The world largest project for rural labor transfer training. Beijing: [The People's Republic of] China Translation \& Publishing Corporation.

Prasad, E. S. (2009). Is the Chinese growth miracle built to last? [The People's Republic of] China Economic Review, 20(1), 103-123.

Reading, C., Shaw, G., et al. (2006). Focusing on ICT in rural and regional education in Australia. Australian Educational Computing, 21(2), 20-24.

Shaohua, Z. (2005). Rural labour migration in [the People's Republic of] China: Challenges for policies. Management of Social Transformations Series, Policy Papers 10, Paris: UNESCO. unesdoc.unesco.org/images/0014/001402/140242e.pdf

Shaw, G. (2011). Person transformation and rural transformation. In V. Chinapah (Ed.), Education for rural transformation (ERT) - National, international, and comparative perspectives (pp. 33-47). Stockholm: Institute of International Education, Stockholm University, Universitetsservice US AB.

Shaw, G. (2012). Education for rural transformation through principals' professional development. In V. Chinapah \& L. Wang (Eds.), Strategies to achieve balanced inclusive educational development: Equity-quality-internationalization (pp. 159-180). Stockholm/Beijing: Universitetservice, Stockholm-Sweden/UNESCO-INRULED.

Sun, D. (2011). Six decades of Chinese middle east studies: A review. Bustan: The Middle East Book Review, 2(1).

Zhang, W. (2012). The other side of the Chinese economic miracle. International Journal of Health Services, 42(1), 9-27. 